\title{
An extreme negative Indian Ocean Dipole event in 2016: dynamics and predictability
}

\author{
Bo Lu ${ }^{1,2} \cdot$ Hong-Li Ren ${ }^{1,2,4}$ (1) Adam A. Scaife ${ }^{3,5} \cdot$ Jie Wu $^{1,2} \cdot$ Nick Dunstone $^{3}$. \\ Doug Smith $^{3} \cdot$ Jianghua Wan $^{1,2} \cdot$ Rosie Eade $^{3}$ - Craig MacLachlan ${ }^{3}$. \\ Margaret Gordon ${ }^{3}$
}

Received: 10 April 2017 / Accepted: 9 September 2017 / Published online: 14 September 2017

(C) The Author(s) 2017. This article is an open access publication

\begin{abstract}
During 2016 boreal summer and fall, a strong negative Indian Ocean Dipole (IOD) event occurred, which led to large climate impacts such as the drought over East Africa. In this study, efforts are made to understand the dynamics of this IOD event and to evaluate real-time IOD predictions from current operational seasonal forecast systems. We show that both the wind-evaporation-SST and thermocline feedback lead to fast IOD growth in boreal summer 2016. Anomalous westerlies over the tropical Indian Ocean warmed the sea surface temperature (SST) over the tropical southeastern Indian Ocean (TSEIO) by reducing local evaporation; and wind induced thermocline deepening increased TSEIO SST by vertical advection. The intraseasonal disturbances in May induced the early subsurface warming and initiated the 2016 IOD. Due to negative cloud-radiation-SST feedback, the 2016 IOD event decayed quickly after October. We also demonstrate the successful real-time IOD predictions by the operational Hadley Center Global seasonal forecasting system version 5 (GloSea5) and the Beijing Climate Center Climate System Model (BCC-CSM1.1m). Resulting
\end{abstract}

Hong-Li Ren

renhl@cma.gov.cn

1 Laboratory for Climate Studies, National Climate Center, China Meteorological Administration, Beijing, China

2 CMA-NJU Joint Laboratory for Climate Prediction Studies, Institute for Climate and Global Change Research, School of Atmospheric Sciences, Nanjing University, Nanjing, China

3 Met Office Hadley Center, Exeter, UK

4 Department of Atmospheric Science, School of Environmental Studies, China University of Geoscience, Wuhan 430074, China

5 College of Engineering, Mathematics and Physical Sciences, University of Exeter, Exeter, UK from the realistic representation of observed air-sea interactions, both models successfully predicted the evolution of the 2016 IOD up to 2 seasons ahead. The skillful prediction is also due to the precursor of the early subsurface warming in the eastern Indian Ocean, which increases intrinsic predictability of the 2016 IOD event. It is also demonstrated that IOD amplitude biases can be reduced by the joint-model prediction. The successful prediction of the 2016 IOD event allowed the East African drought to be predicted 4-6 months ahead. Our study reveals that current operational climate models can give useful warning of impending IOD events and impending climate extremes.

Keywords Indian Ocean Dipole - Air-sea interaction · East African drought $\cdot$ Seasonal prediction

\section{Introduction}

The Indian Ocean dipole (IOD) is a zonal dipole in the tropical Indian Ocean sea surface temperature (SST) varying on the interannual timescale (Saji et al. 1999; Webster et al. 1999). A positive (negative) IOD is associated with a cooling (warming) off the Sumatran coast and a warming (cooling) over the western equatorial Indian Ocean. The IOD has attracted much attention since the extreme 1997 positive IOD event which brought severe floods to East Africa and droughts to Indonesia (Webster et al. 1999). The interaction of the IOD with the Asian monsoon and the El Niño/Southern Oscillation (ENSO) has also been extensively studied (Ashok et al. 2001, 2003, 2004; Yu et al. 2002; Behera and Yamagata 2003; Gadgil et al. 2004; Kug and Kang 2006; Ashok and Saji 2007; Yuan et al. 2008; Izumo et al. 2010; Luo et al. 2010). By exciting atmospheric planetary waves, 
IOD influences can even reach remote regions (e.g. Saji and Yamagata 2003).

In 2016, an extreme negative IOD event occurred, it is the strongest negative IOD in the period since 1980 according to NOAA Optimum Interpolation Sea Surface Temperature V2 dataset (OISSTv2; Reynolds et al. 2002), with the peak Indian Ocean Dipole Mode index (DMI; Saji et al. 1999) reaching $-1.5{ }^{\circ} \mathrm{C}$ (see Fig. 1a). As shown in Fig. 2a, the 2016 boreal fall SST anomalies feature a strong warming off the coast of Sumatra $\left(>1{ }^{\circ} \mathrm{C}\right)$, and a moderate cooling over the equatorial western Indian Ocean $\left(<-0.5^{\circ} \mathrm{C}\right)$. This strong IOD led to large climate influences such as the East African drought in 2016. During the East African short rain season (from October to December), the rainfall was reduced by (a)

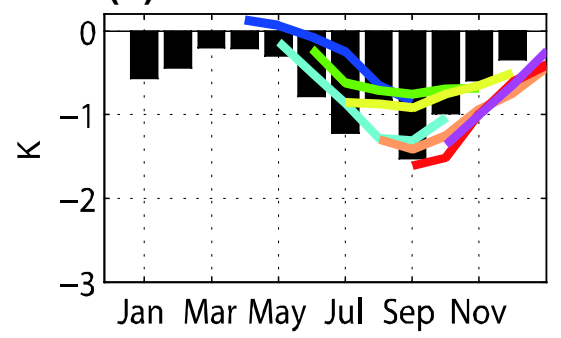

(d) $\quad$ U850 BCC

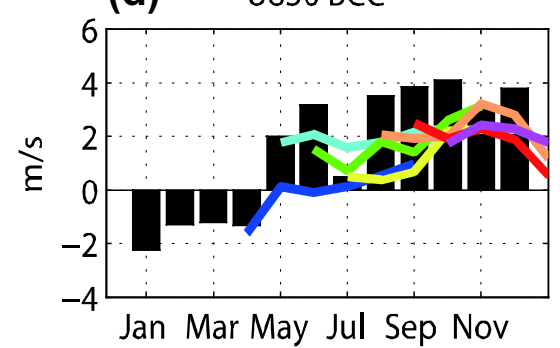

(g) $\quad \mathrm{N} 3.4 \mathrm{BCC}$

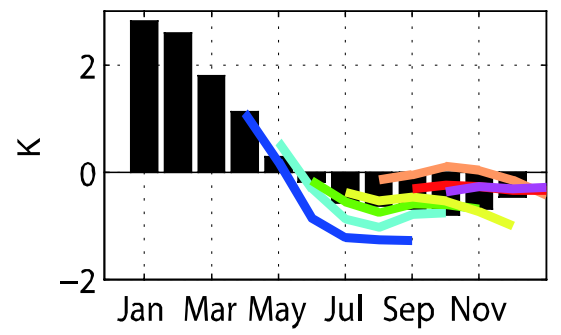

(j) $\quad \mathrm{ESOI} B C C$

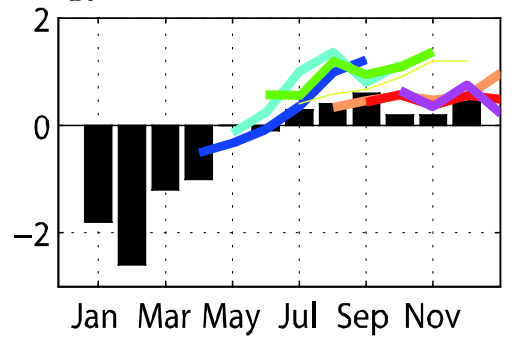

(b) IOD GloSea5

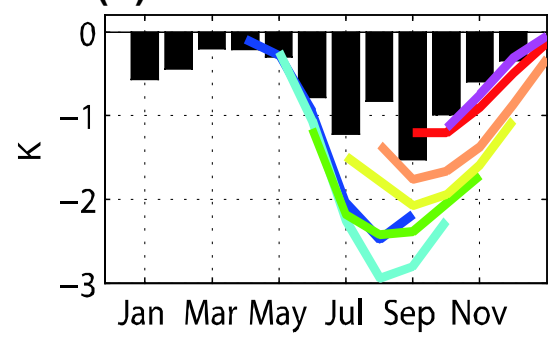

(e) U850 GloSea5

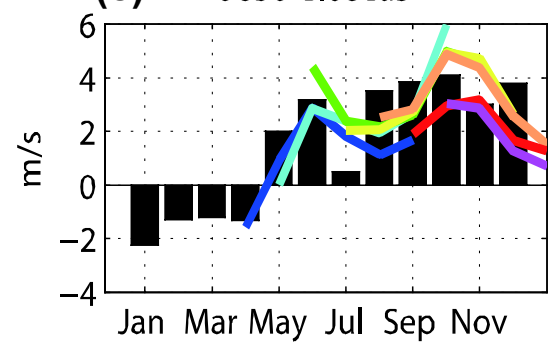

(h) N3.4 GloSea5

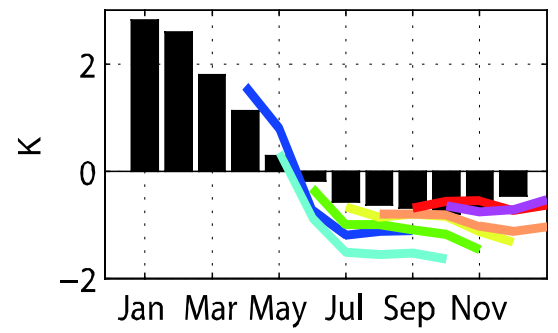

(k) ESOI GloSea5

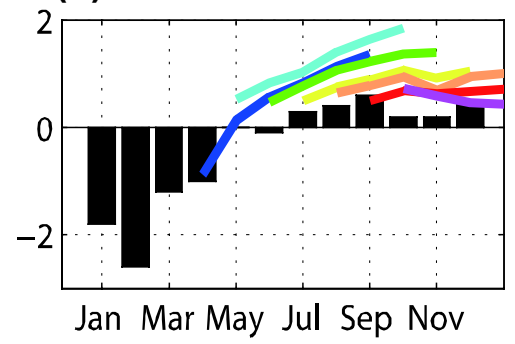

(c)

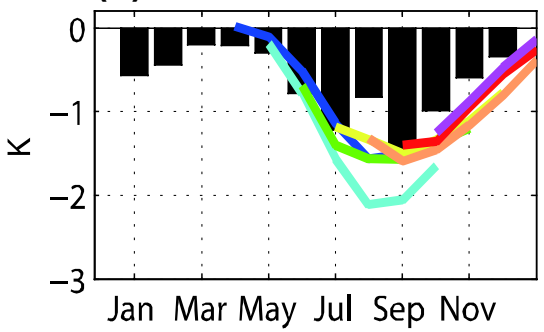

(f)

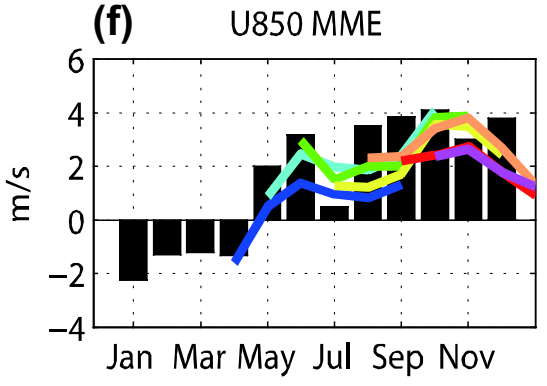

(i)
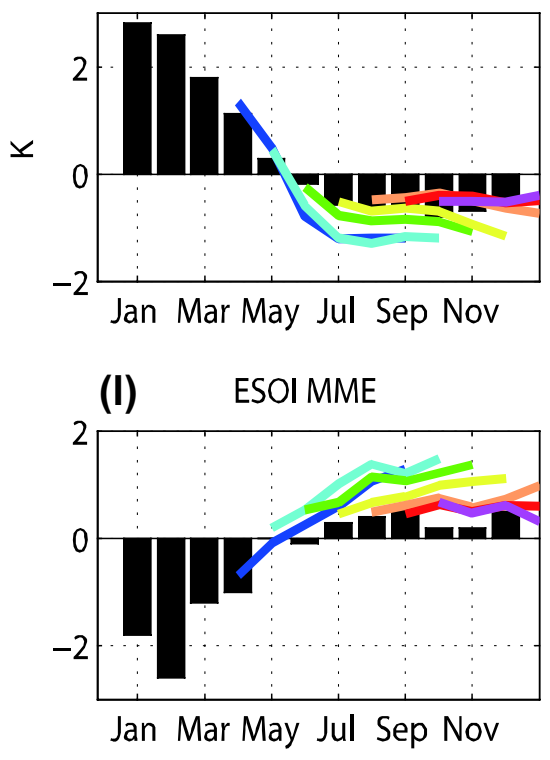

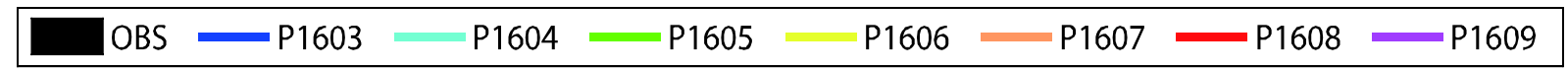

Fig. 1 Observed (bars) and predicted (curves) IOD index (a-c), equatorial zonal wind anomaly $(\mathbf{d}-\mathbf{f})$, Niño3.4 anomaly $(\mathbf{g}-\mathbf{i})$ and equatorial Southern Oscillation index $(\mathbf{j}-\mathbf{l})$ by BCC-CSM1.1m (left panel), GloSea5 (middle panel) and their average (right panel) in 2016. The real-time predictions were initialized in March (blue), April (light blue), May (green), June (yellow), July (orange), August (red) and September (purple), respectively 
(a)

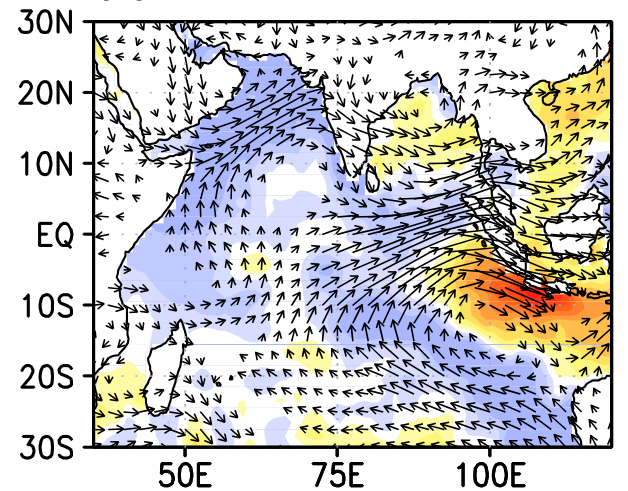

(b) $\quad \mathrm{BCC}$

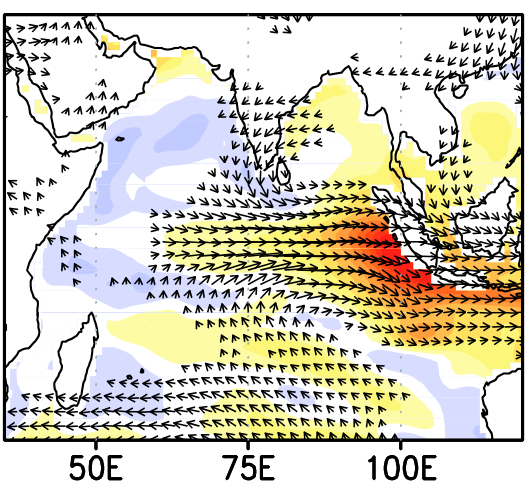

(c) GloSea5

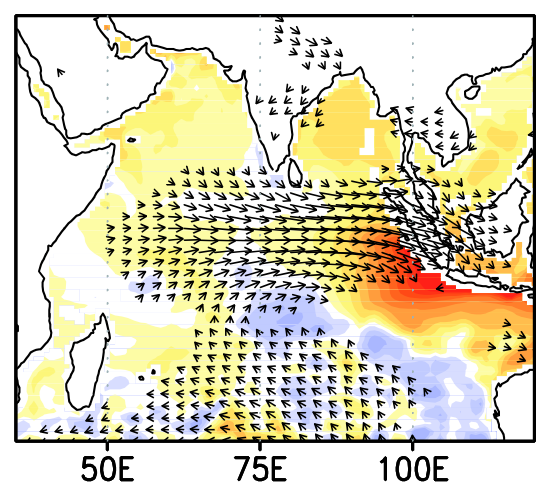

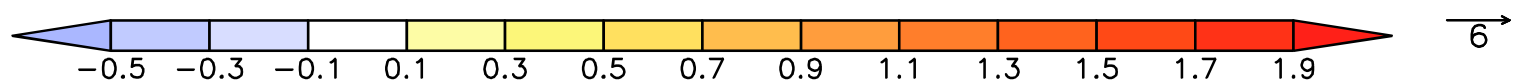

Fig. 2 The patterns of SST and $850 \mathrm{hPa}$ wind anomalies during boreal fall 2016 in the observations (a) and the real-time predictions by BCCCSM1.1m (b) and GloSea5 (c) initialized in August. Wind anomalies less than $0.6 \mathrm{~m} / \mathrm{s}$ have been omitted for clarity

$1 \mathrm{~mm} /$ day (Fig. 3a), with some regions recording below $50 \%$ of normal rainfall. As reported by the Inter-Agency Working Group (IAWG) in December 2016, over 15 million people in Somalia, Ethiopia and Kenya were experiencing devastating drought, food insecurity and unsafe drinking water. Thus, it is important to investigate the dynamics and predictability of this 2016 extreme negative IOD event.
The dynamics of IOD events are not completely understood. Dommenget (2011) argued that IOD cannot be distinguished from red noise based on a null hypothesis. A number of studies have pointed out the dependence of IOD on ENSO (e.g., Allan et al. 2001; Dommenget and Latif 2002; Baquero-Bernal et al. 2002; Yu and Lau 2004; Wang and Wang 2014), emphasizing the El Niño induced anomalous (a)

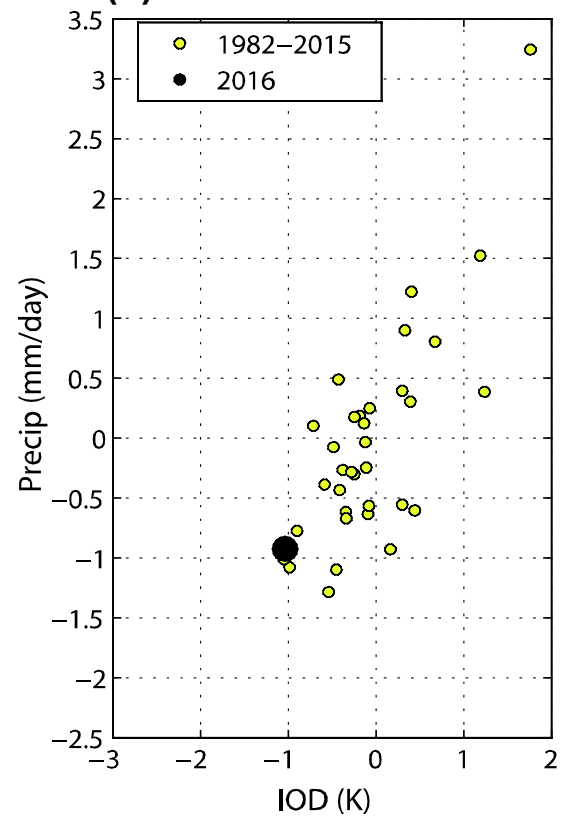

(b)

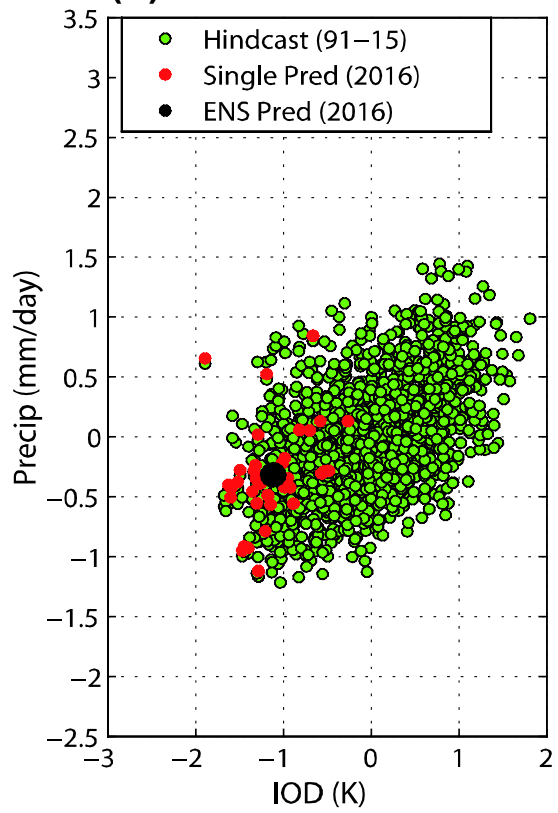

GloSea5

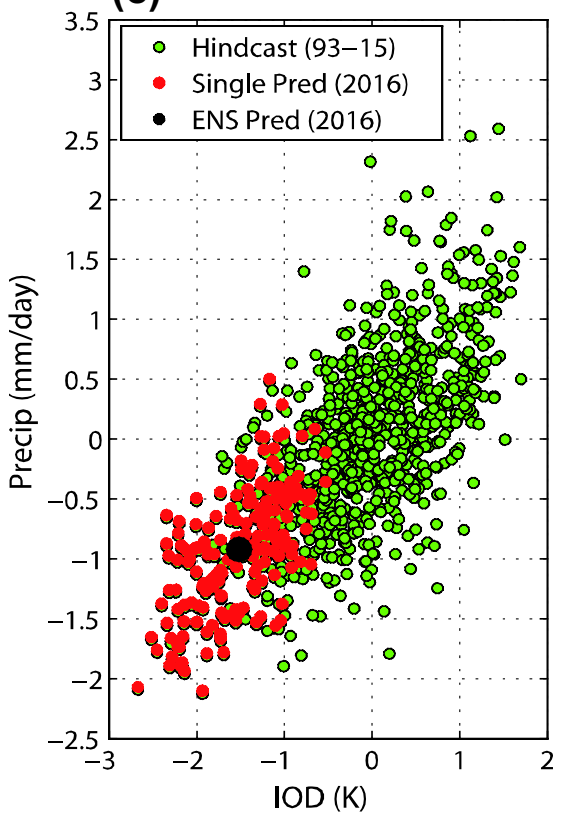

Fig. 3 Scatter plots of East African precipitation anomalies (land portion within $10^{\circ} \mathrm{S}-10^{\circ} \mathrm{N} ; 30^{\circ} \mathrm{E}-45^{\circ} \mathrm{E}$ ) during the short rain season (October, November and December) against the IOD index during boreal fall in the observations (a) and predictions by BCC-CSM1.1m (b) and GloSea5 (c) initialized in boreal summer (June, July and
August). The hindcast experiments and the 2016 real-time prediction are shown in green and red circles, respectively. The black circle in a represents the observation for the 2016 negative IOD case. The black circles in b, c indicate the ensemble mean prediction for the 2016 negative IOD case by BCC-CSM1.1m and GloSea5, respectively 
easterly wind off Sumatran coast during ENSO development in boreal summer. However, given the fact that several IOD events occurred in the absence of ENSO forcing, other studies suggest IOD as an inherent mode of internal variability within the Indian Ocean basin (Behera et al. 1999; Webster et al. 1999; Ashok et al. 2003; Yamagata et al. 2003). In a recent modeling study, one-third of the total IOD variance was due to ENSO forcing and the remaining arose from internal variability in the absence of ENSO (Yang et al. 2015). Coincident with the extreme negative IOD in 2016, the large 2015/2016 joint record El Niño decayed quickly and transited into a weak La Niña state over the tropical Pacific. Hence it is necessary to investigate the potential roles of internal variability in the Indian Ocean and the weak La Niña to explain the evolution of the 2016 IOD. In addition to ENSO, other possible triggers have also been proposed for initiating IOD events, such as the Indonesian Throughflow (Annamalai et al. 2003), the severe cyclone over the Bay of Bengal (Francis et al. 2007), the Hadley circulation over the western Pacific (Kajikawa et al. 2003), the subtropical IOD (Feng et al. 2014) and springtime Indonesian rainfall (Wang et al. 2016). The key role of windevaporation-SST (WES) and thermocline feedbacks are suggested to be fundamental to IOD growth (Li et al. 2003; Liu et al. 2011). However, not all the historical IOD events were accompanied by the WES and thermocline feedbacks. For example, WES feedback was inactive during 1997 IOD event. Therefore, the extreme negative IOD event in 2016 offers a good opportunity to further validate the dynamics of IOD formation.

The predictability of IOD events has been assessed for several coupled climate models (Luo et al. 2005, 2007; Song et al. 2008; Zhao and Hendon 2009; Shi et al. 2012; Liu et al. 2017). The lead time for skillful SST prediction is 5-6 months for the western Indian Ocean (IODW; $10^{\circ} \mathrm{S}-10 \mathrm{~N}^{\circ}, 50^{\circ} \mathrm{E}-70^{\circ} \mathrm{E}$ ) and 3-4 months for the eastern Indian Ocean (IODE; $\left.10^{\circ} \mathrm{S}-0^{\circ}, 90^{\circ} \mathrm{E}-110^{\circ} \mathrm{E}\right)$. In general, skillful predictions of Dipole Mode Index (DMI) can only be made one season ahead (Shi et al. 2012; Liu et al. 2017). There is a winter predictability barrier (Luo et al. 2007), with a rapid drop of skill for IOD predictions across boreal winter. Although the prediction skill by dynamical coupled models is comparable to simple linear statistical models (Dommenget and Jansen 2009), higher skill can be achieved for larger IOD events. For example, the strong 2006 and 2007 positive IOD events were successfully predicted by SINTEX-F 3 seasons ahead owing to the oceanic subsurface memory in the South Indian Ocean (Luo et al. 2008). Considering the severe societal impacts of the strong 2016 negative IOD event (IAWG 2016), it is important to evaluate its real-time operational prediction by current operational seasonal prediction models. It is also interesting to study whether the prediction of impending extremes, such as the East African drought, can benefit from successful IOD predictions.

The remainder of the paper is organized as follows. Section 2 describes the observational, hindcast and real-time forecast datasets used in the study. In Sect. 3, we study the dynamics of the evolution of the 2016 IOD event. Real-time prediction of the 2016 IOD and its climate impacts are evaluated in Sect. 4. Finally, a summary and discussion of the results is given in Sect. 5 .

\section{Data and methodology}

SST observations are taken from OISSTv2 (Reynolds et al. 2002), and the NCEP Global Ocean Data Assimilation System (GODAS; Behringer et al. 1998) is analyzed for the heat budget of the upper ocean. Monthly precipitation over land and ocean are obtained from the CPC Merged Analysis of Precipitation (CMAP; Xie and Arkin 1997) covering the period since 1979, while the Global Precipitation Climatology Centre monthly precipitation dataset (GPCC; Schneider et al. 2011) is utilized to study the precipitation only over land. Observed atmospheric circulation is obtained from the National Centers for Environmental Prediction/Department of Energy (NCEP/DOE) Reanalysis 1 (Kalnay et al. 1996).

In this study, we assess the IOD prediction by two operational seasonal prediction models, namely Global seasonal forecasting system version 5 (GloSea5) and the Beijing Climate Center Climate System Model (BCC-CSM1.1m). BCC-CSM1.1m is employed as the current operational model for seasonal prediction in Beijing Climate Center ( $\mathrm{Wu}$ et al. 2010). Its ocean component is developed by modifying MOM4 from Geophysical Fluid Dynamics Laboratory (Griffies et al. 2004). Its horizontal resolution is $1^{\circ} \times 1^{\circ}$ poleward of $30^{\circ} \mathrm{N}$ and $30^{\circ} \mathrm{S}$, incrementally increasing to $1 / 3^{\circ}$ latitude within $30^{\circ} \mathrm{N}$ and $30^{\circ} \mathrm{S}$. This ocean model has 40 vertical layers and includes dynamic and thermodynamic Sea Ice Simulator (Winton 2000). The atmospheric component is the BCC_AGCM2.2 at T106 horizontal resolution and 26 vertical layers (Wu et al. 2008), and the land model is BCC_ AVIM (Ji et al. 2008) with a same horizontal resolution as the atmospheric model. The real-time forecast is performed at the beginning of every month, with 24 members per prediction by lagged initial dates ( 15 members) and singular vector perturbation method ( 9 members; Kleeman et al. 2003). BCC-Godas ocean reanalysis is used to initialize the ocean (Liu et al. 2005), while initial atmosphere and sea ice conditions are nudged toward NCEP reanalysis (Kalnay et al. 1996) and NOAA Optimum Interpolation Ice Concentration data (Reynolds et al. 2002), respectively. A monthly hindcast set covers the period from 1991 to 2014, with the same experimental design as the real-time forecast. 
GloSea5 is the operational seasonal forecasting system of the Met Office (MacLachlan et al. 2015). The coupled HadGEM3 model is used in GloSea5. The atmosphere component uses Met Office Unified Model (Brown et al. 2012) atmosphere, and the ocean component uses NEMO (Nucleus for European Modelling of the Ocean; Madec 2008). GloSea5 uses the N216 resolution $\left(0.8^{\circ}\right.$ in latitude and $0.5^{\circ}$ in longitude) for the atmosphere, and the ORCA0.25 grid $\left(0.25^{\circ}\right)$ for the ocean. There are 85 vertical levels for the atmosphere and 75 levels for the ocean. The model contains no flux corrections or relaxation to climatology. GloSea5 produces 210-day long real-time seasonal forecasts initialized every day with two members. The initial atmospheric conditions are obtained from the Met Office 4D-Var data assimilation system (Rawlins et al. 2007), and the ocean and sea ice conditions are initialized from the short-range ocean forecasting and data assimilation system (MacLachlan et al. 2015). As an effort to obtain the model climatology and correct the mean state bias, a hindcast set initialized on the 1st, 9th, 17th and 25th days every month is completed from 1993 to 2015 . Following the weighting strategy described in Arribas et al. (2011), the daily climatology is weighted average of the closest hindcast initialization dates. More details can be found in MacLachlan et al. (2015). Additional hindcast experiments with 24 members were performed for boreal summer, initialized on 25 April, 1 May and 9 May from 1992 to 2011. Each start date has eight ensemble members with different stochastic parameterization of model physics (Tennant et al. 2011), thus totaling 24 ensemble members per year. The GloSea5 Ocean and Sea Ice Analysis (1989-2011) supplies initial conditions for the ocean and sea ice, and ERA-Interim reanalysis data is used to initialize the atmosphere and land surface in the hindcast members. This extra hindcast dataset with a larger ensemble size is utilized to evaluate the historical IOD prediction skill by GloSea5.

\section{Dynamics of the 2016 IOD event}

Figure 1a shows the evolution of the 2016 IOD event (Saji et al. 1999). At the beginning of 2016, the Indian Ocean SST was passively modulated by the 2015/2016 super El Niño. It is well known that the Indian Ocean often warms following El Niño (Weare 1979) due to suppressed atmospheric convection and intensified surface energy flux. This basin wide warming was observed from January to April 2016, with the positive SST anomalies in both poles of the IOD (Figure not shown). Following the rapid decay of the 2015/2016 El Niño in boreal spring (Fig. 1g), SST over the western Indian Ocean dropped to $0.5^{\circ} \mathrm{C}$ below normal. However, IODE SST remained warmer than normal throughout 2016, which is similar to the persistent IODE warming in 1998 and 2010 after the 1997/1998 and 2009/2010 El Niño events, respectively. The southeastern Indian ocean warmed up again during boreal summer 2016 , and reached $1{ }^{\circ} \mathrm{C}$ above normal in September 2016, forming the strongest negative IOD event occurred since the 1980s (Fig. 1a). Thus, IODE played a more important role in the 2016 IOD than the western pole, and we focus on the dynamics of SST evolution in the tropical southeastern Indian Ocean.

A negative (positive) IOD event is often accompanied by a westerly (easterly) wind anomalies over the equatorial Indian Ocean, suggesting a role for local air-sea interaction (Saji et al. 1999; Yamagata et al. 2004). Consistent with this, a strong westerly wind anomaly was evident over the equatorial central to eastern Indian Ocean in 2016 (Fig. 2a). This westerly wind anomaly was pronounced from May to December 2016 (Fig. 1d). The northwesterly wind anomaly off the coast of Sumatra (Fig. 2a) reduced the local climatologic southeasterly during boreal summer, resulting in reduced local evaporation and a warmer IODE. According to Gill's solution (1980), the warming in IODE also induced an anomalous cyclone over the southeastern Indian Ocean (Fig. 2a), leading to a stronger northwesterly wind anomaly and further warming off Sumatran coast. We quantitatively evaluate the latent heat flux changes over IODE. As shown in Fig. 4, the weakening of local wind speed led to a reduction of latent heat loss which warmed IODE during boreal summer. The above wind-evaporation-SST feedback was suggested to be important for IOD growth ( $\mathrm{Li}$ et al. 2003;

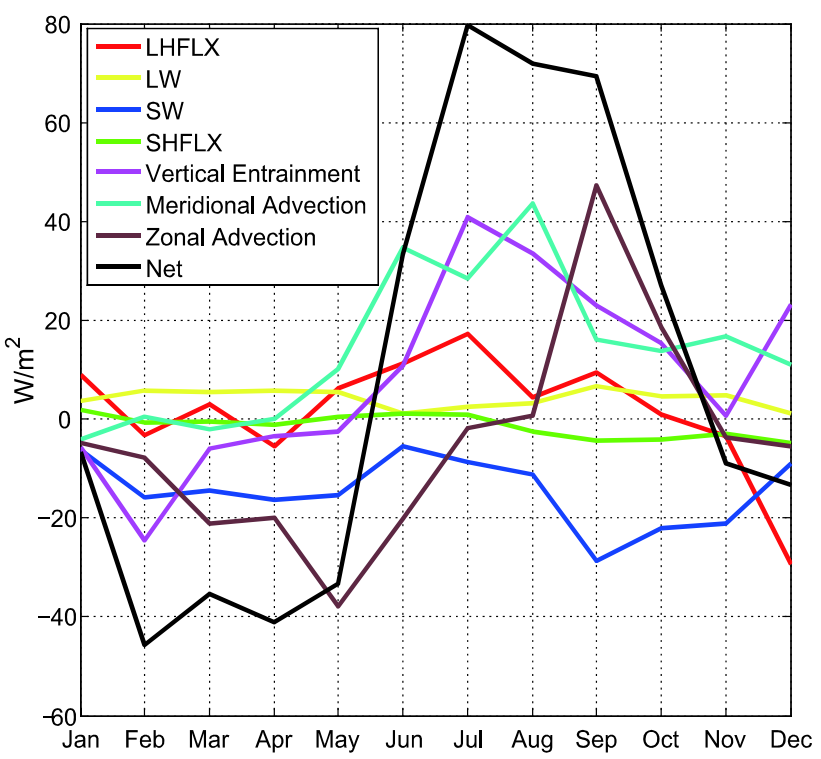

Fig. 4 The observed anomalies of latent heat flux (red), net downward long wave radiation at surface (yellow), net downward short wave radiation at surface (blue), sensible heat flux (green), vertical entrainment (purple), meridional advection (cyan), zonal advection (brown) and the net energy flux (black) over tropical southeastern Indian Ocean $\left(90^{\circ} \mathrm{E}-110^{\circ} \mathrm{E}, 10^{\circ} \mathrm{S}-\right.$ Equator $)$ in 2016 
Liu et al. 2011). Here, the fast growth of 2016 IOD event validates this hypothesis and also confirms IOD as a natural climate mode. It should be noted that WES feedback is positive only when the climatological southeasterly wind is pronounced in boreal summer and early fall. Although the equatorial westerly wind anomaly remained strong even in December 2016, the WES feedback became negative (Fig. 4) since the climatological wind turns northwesterly during boreal winter.

Along with the thermodynamic WES feedback, the anomalous equatorial westerly can also warm IODE by inducing a thermocline deepening and ocean warming. This thermocline feedback was first proposed in the eastern equatorial Pacific (EEP), where the easterly trade wind is strong and the thermocline is shallow. However, the thermocline in the Indian Ocean is relatively flat and deep due to the annual mean westerly wind. Thus, thermocline feedback is generally weaker in the Indian than the Pacific Ocean. However, the thermocline feedback is active from July to November (e.g. reviewed by Schott et al. 2009), when the mean upwelling is strong and the mean thermocline is shallow in the tropical eastern Indian Ocean. As shown in Fig. 4, the vertical advection of the anomalous subsurface warm water by the mean upwelling was pronounced from July to October, contributing to the peak phase of 2016 IOD. It is demonstrated that the impact of thermocline feedback on the 2016 IOD event is larger than WES feedback, which is consistent with previous studies (Murtugudde et al. 2000). We also note that the downward solar radiation is reduced with the IODE warming throughout 2016 (Fig. 4), indicating negative cloud-SST feedback. During boreal winter, this cloud-SST feedback and negative WES feedback terminated the IODE warming quickly, explaining the fast decay of 2016 negative IOD event (Fig. 1a).

Besides the WES and thermocline feedbacks during boreal summer and fall, the precursor of the 2016 extreme IOD event in late spring is also investigated. Prior to the IOD SST development, the tropical westerly wind anomaly occurred in May and June over the Indian Ocean basin (Fig. 1d), which initiated the early subsurface warming in the tropical southeastern Indian Ocean (Fig. 5). We further investigate the early zonal wind anomaly among historical IOD events. As shown in Fig. 6a, the significant correlation (0.62) is evident between the zonal wind and subsurface heat content anomalies in May and June at the 99\% confidence level using a student-t test. Also, the early subsurface heat content anomaly in May and June is well correlated (0.50) with the SST in the tropical southeastern Pacific during the mature phase in boreal fall (Fig. 6b), implying the ocean memory and the effective thermocline feedback during IOD growth. It should be noted that the early westerly wind anomaly acted as an precursor for the strong negative IOD events in 1998 and 2016. However, the activation of

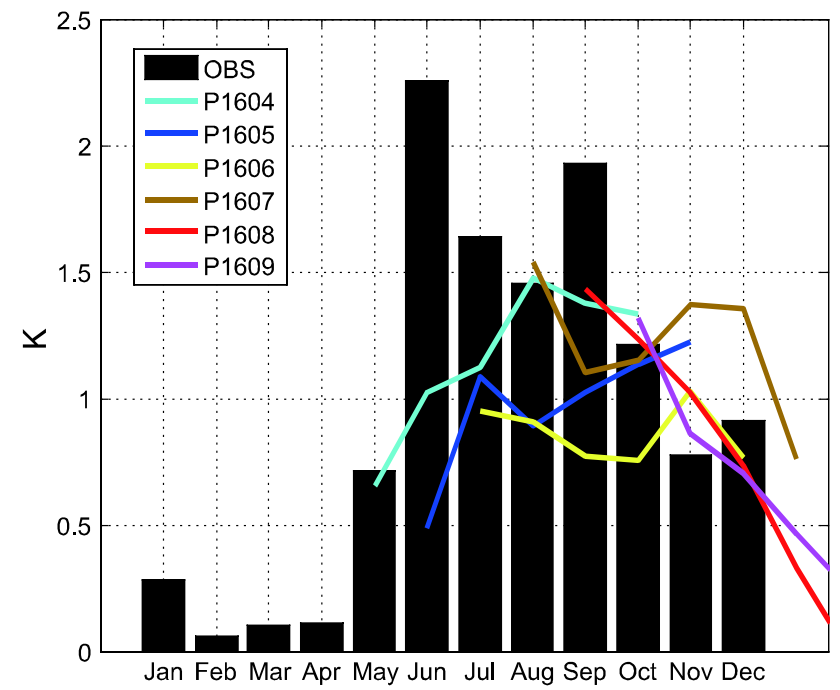

Fig. 5 Heat content anomalies of the upper ocean (0-200 m) over the tropical southeastern Indian Ocean in the observations (bars) and the real-time predictions by BCC-CSM1.1m (curves) in 2016. The predictions initialized in April, May, June, July, August and September are indicated by the light blue, blue, yellow, orange, red and purple curves, respectively
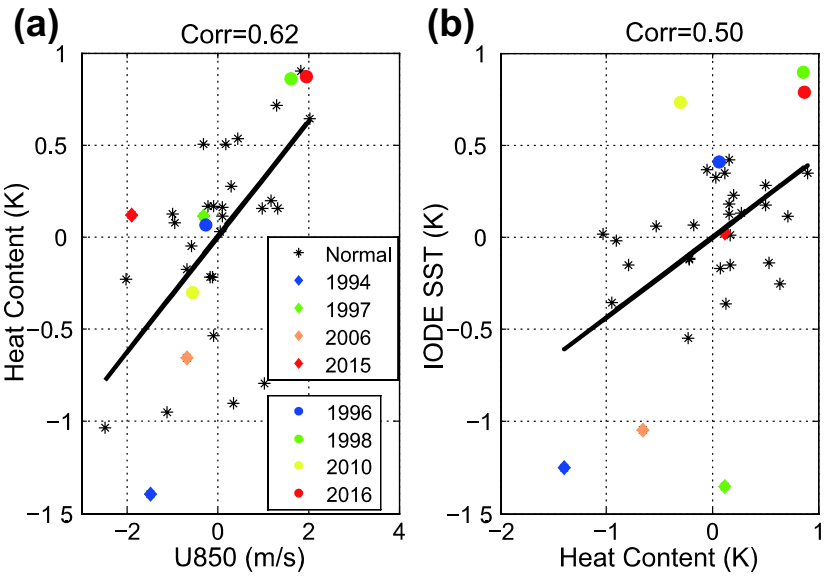

Fig. 6 The scatter plots of the heat content anomaly $(0-200 \mathrm{~m})$ against the zonal wind anomaly at $850 \mathrm{hPa}$ (a) and the SST anomaly against the heat content anomaly (b) over $\left[90^{\circ} \mathrm{E}-110^{\circ} \mathrm{E}\right.$; $10^{\circ} \mathrm{S}-$ Equator]. Note that the heat content and zonal wind anomalies are averaged in May and June, while the IODE SST anomaly is averaged from September to November. Four strongest positive IOD years $(1994,1997,2006,2015)$ and four strongest negative IOD years (1996, 1998, 2010 and 2016) since 1980s are indicated by the colorful symbols based on the IOD index (Saji et al. 1999) averaged from September to November. The straight lines represent the linear fitting line. The correlation coefficients are denotes by the numbers on the top of each figure

the negative IOD events in 1996 and 2010 cannot be attributed to early westerly wind or early subsurface warming, implying the existence of other precursors, such as oceanic 
equatorial Kelvin waves and the variations of ITCZ rainfall (Rao et al. 2009).

We now investigate the origin of the early westerly wind in May. ENSO has been suggested to trigger IOD by modulating zonal winds off the Sumatran coast (e.g. Dommenget and Latif 2002). A weak La Niña coincided with the 2016 IOD (Fig. 1g). The atmospheric response to La Niña is characterised by the equatorial Southern Oscillation index (ESOI; http://www.cpc.ncep.noaa.gov/data/indices/), which measures the standardized anomaly of the difference between the area-average sea level pressure in an area of the eastern equatorial Pacific $\left(80^{\circ} \mathrm{W}-130^{\circ} \mathrm{W}, 5^{\circ} \mathrm{N}-5^{\circ} \mathrm{S}\right)$ and an area over Indonesia $\left(90^{\circ} \mathrm{E}-140^{\circ} \mathrm{E}, 5^{\circ} \mathrm{N}-5^{\circ} \mathrm{S}\right)$. As shown in Fig. 1j, the ESOI index remained negative from January to April, indicating a slowing of the Walker Circulation induced by the previous 2015/2016 El Niño. As the eastern Pacific developed into a weak La Niña state in July (Fig. 1g), ESOI turned positive and reached a peak in September. The resulting strengthening of the Walker Circulation helped to reinforce the anomalous westerly wind over the equatorial Indian Ocean during boreal fall. However, the La Niña induced atmospheric changes were moderate, with ESOI only reaching 0.6 standard deviation during boreal fall 2016. Furthermore, the westerly wind was evident as early as May and June (Fig. 1d) when ESOI was neutral (Fig. 1j), implying that the initiation of westerly wind in May and June was independent of the La Niña forcing. The westerly wind anomaly in 2016 may simply result from internal variability within the Indian Ocean, with the weak La Niña playing a secondary role.

Since the initiation of 2016 negative IOD was unrelated to ENSO forcing, we investigate other possible triggers. Wang et al. (2016) suggested that positive (negative) IOD can be initiated by springtime Indonesian rainfall deficit (surplus) in the absence of ENSO. Figure 7b, d show the intraseasonal evolution of zonal wind at $850 \mathrm{hPa}$ and outgoing longwave radiation (OLR) in 2016. The above normal convection over Indonesian was observed during late spring, which induced the westerly wind anomaly that is important for IOD dynamics. Furthermore, the Indonesian rainfall anomaly was found to be originated from the western Indian Ocean. The eastward propagation of Madden-Julian oscillation (MJO) was clearly evident in May (Fig. 7). Similar feature was also evident in the extreme 1998 IOD event (Fig. 7a, c). In fact, the amplitude of MJO (Wheeler and Hendon 2004) in May 1998 and 2016 reached 3.6 and 1.6, respectively, indicating strong MJO activities. Although IOD and MJO have different time scales, the IOD-MJO interaction has been documented by many studies. Shinoda and Han (2005) found that MJO activity is strongly reduced during positive IOD years. The termination of 2003 and 2007 positive IOD events was suggested to be a result from convection-enhancing MJOs which deepen the thermocline in the southeastern equatorial
Indian Ocean (Rao et al. 2009). Also, easterlies associated with the convection-suppressing phase of of MJO initiated the positive IOD event in 2006 (Rao et al. 2009). Here, we suggested that the active phase of MJO could induce strong westerly wind in late spring, which might activate the negative IOD events in 1998 and 2016 by initiating the early subsurface warming.

\section{Evaluations of real-time predictions of the 2016 IOD}

It has been shown the air-sea interaction is key for the 2016 negative IOD event. Now we demonstrate to what extent our operational coupled models can capture the IOD dynamics and predict the 2016 negative IOD event. Figure 2b, c show the real-time predictions of boreal fall SST and wind anomalies by BCC-CSM1.1m and GloSea5, respectively. The strong warming off the Sumatran coast was well predicted by both models, and BCC-CSM1.1m also captured the weak cooling over the western Indian Ocean. The strong anomalous westerly wind along the equator was successfully predicted by both models, indicating the realistic air-sea interaction. Similar to the observation, the IODE SST warming induced the northwesterly wind off the Sumatran coast as a part of the associated cyclone over southeastern Indian Ocean, which further warmed IODE SST by reducing the local surface wind speed. This implies that the observed WES feedback was also well reproduced by both models, which helped to drive the successful 2016 IOD predictions.

Both models also predicted remote factors, such as the 2016 weak La Niña. As shown in Fig. 1g, although the Pacific cooling was overestimated when initialized in March and April, the weak La Niña is well predicted after May. Furthermore, the La Niña induced weak atmospheric response was also well reproduced. The predicted strengthening of the Walker Circulation, as indicated by a positive ESOI (Fig. 1j, k, 1), reinforced the westerly wind over the Indian Ocean in agreement with the observations. Consistent with the Niño 3.4 predictions, the atmospheric responses are overestimated by both models when initialized in boreal spring. However, the observed moderate positive ESOI is well reproduced when initialized in boreal summer and fall. Thus, a secondary role of the 2016 La Niña is well represented in the predicted 2016 IOD growth, consistent with observations.

Observational evidence shows that the 2016 IOD event was triggered by active MJOs in May. The intraseasonal perturbation is usually difficult to be captured by seasonal prediction models. The MJO-induced westerly wind anomaly in May 2016 was underestimated by GloSea5 (Fig. 1e). However, BCC-CSM1.1m correctly predicted the initiation of westerly wind anomaly 1 month ahead (light blue curve 

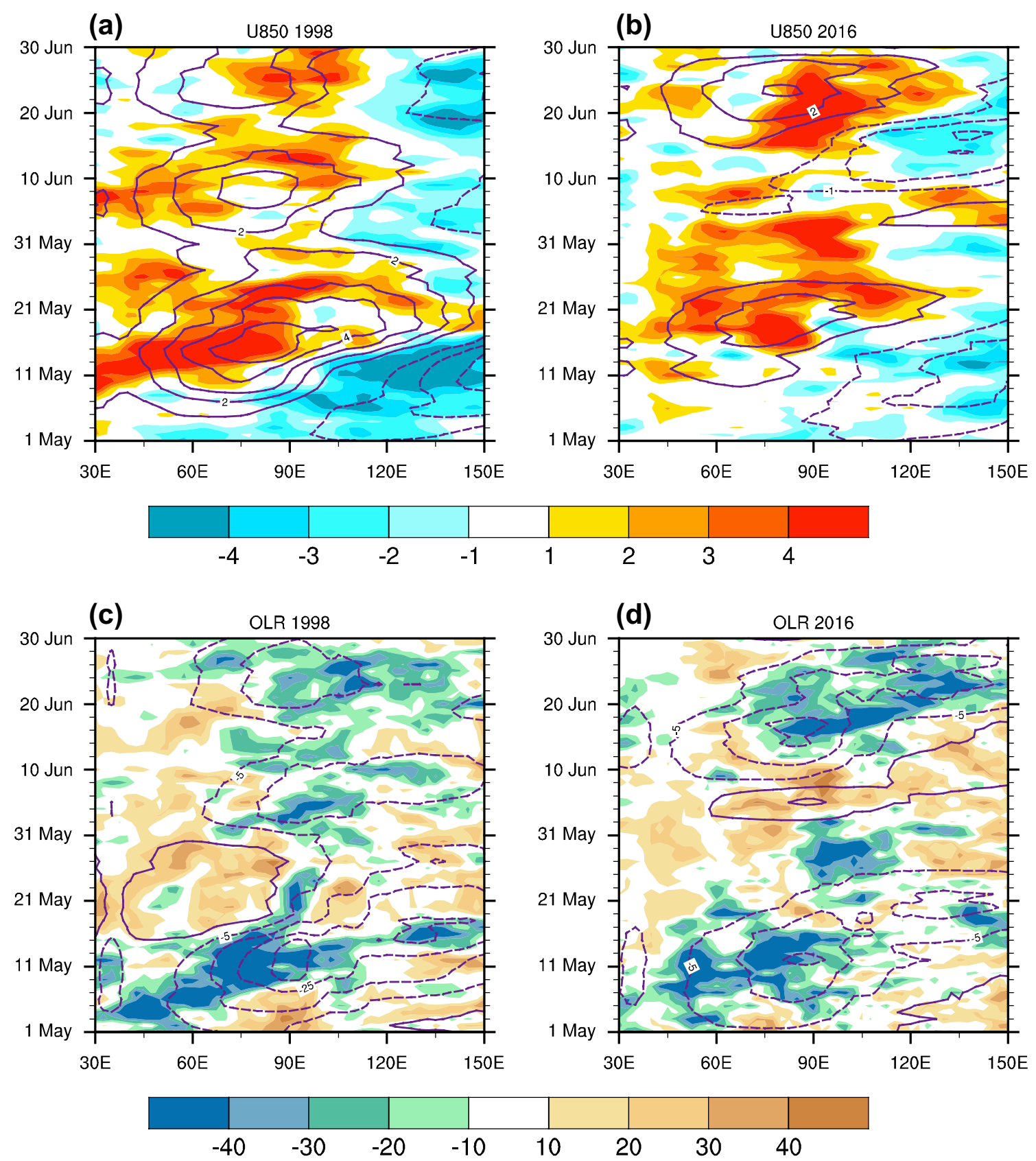

Fig. 7 Time-longitude plots of observed zonal wind anomalies (upper panel; $\mathrm{m} / \mathrm{s}$ ) and outgoing longwave radiation (lower panel; W/ $\left.\mathrm{m}^{2}\right)$ along the equator $\left(10^{\circ} \mathrm{S}-10^{\circ} \mathrm{N}\right)$ during the strong negative IOD

in Fig. 1d). Similar to observations, the predicted westerly wind onset in BCC-CSM1.1 $\mathrm{m}$ is unrelated to the concurrent 2016 La Niña, because the predicted atmospheric response was unclear in May (light blue curve in Fig. 1j). This implies a possible impact of internal intraseasonal processes on IOD initiation in predictions by BCC-CSM1.1m.

The real-time prediction plumes of DMI are given in Fig. 1b, c. It is interesting that early warning of the extreme 2016 negative IOD can be predicted as early as March 2016. years of $1998(\mathbf{a}, \mathbf{c})$ and $2016(\mathbf{b}, \mathbf{d})$. The contours indicate the reconstructions by Real-time Multivariate MJO Indices (Wheeler and Hendon 2004)

Both models correctly predicted the quick onset, fast decay and peak season of the 2016 negative IOD. However, amplitude biases are evident in both models. BCC-CSM1.1m underestimated the 2016 negative IOD amplitude, while GloSea5 over-predicted it, especially when initialized in spring. Similar amplitude biases are also seen during other years in the 24 members hindcast experiments by both models (Fig. 8). We suggest that IOD amplitude bias is due to the mean state bias in tropical Indian Ocean. For GloSea5, 


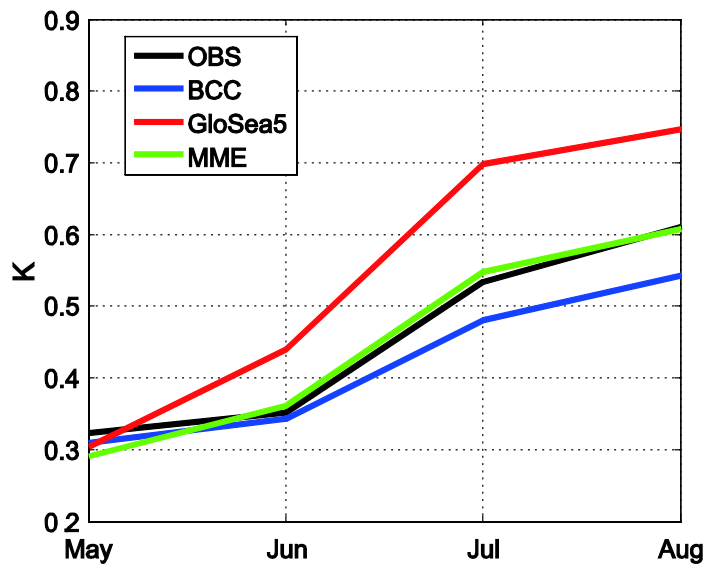

Fig. 8 Standard deviation of IOD index in the observations (black curve) and hindcast experiments initialized in May by BCCCSM1.1m (blue), GloSea5 (red) and their average (green)

the mean thermocline is too shallow in the eastern equatorial Indian Ocean (Johnson et al. 2017), leading to an overestimation of thermocline feedback and the resultant IOD amplitude. In contrast, for BCC-CSM1.1m, the mean thermocline is too deep in the eastern equatorial Indian Ocean (Fig. 9) and hence the SST response is too weak. The IOD amplitude bias is reduced in the joint-model mean (Figs. 1c, 8), because the mean state biases in the two models cancel.

The IOD prediction skill is quite low at current level, with correlation of 0.5 around 3-4 months for most models (Shi et al. 2012; Liu et al. 2017). The overall IOD prediction skill by BCC-CSM1.1m is not significantly higher than other models, with the ACC skill quickly dropping under 0.5 after 3 months (not shown). Thus, the successful prediction of 2016 IOD event is partly due to the intrinsic predictable components inherent to this event. Figure 10 demonstrates the hindcast of IOD initialized in May and November by
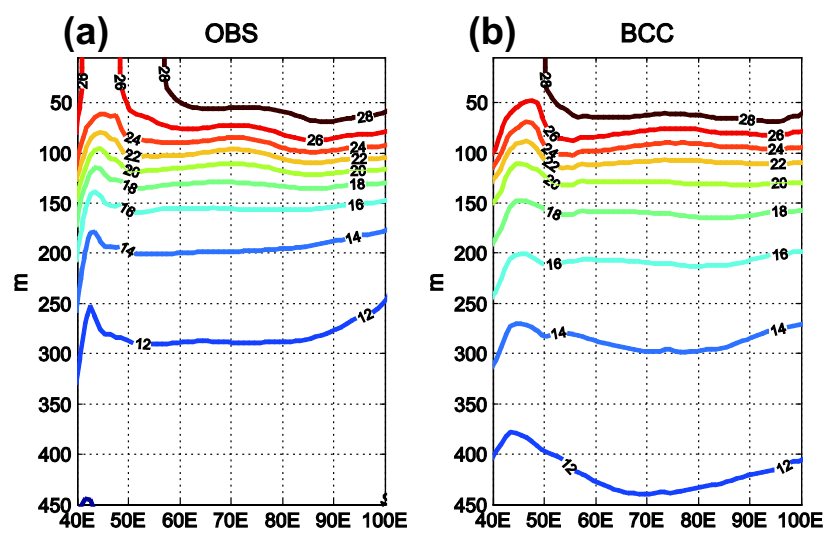

Fig. 9 Vertical profiles of climatologic Indian Ocean temperature along equator $\left(5^{\circ} \mathrm{S}-5^{\circ} \mathrm{N}\right)$ during boreal summer in the observation (a) and the simulation by BCC-CSM1.1m (b)

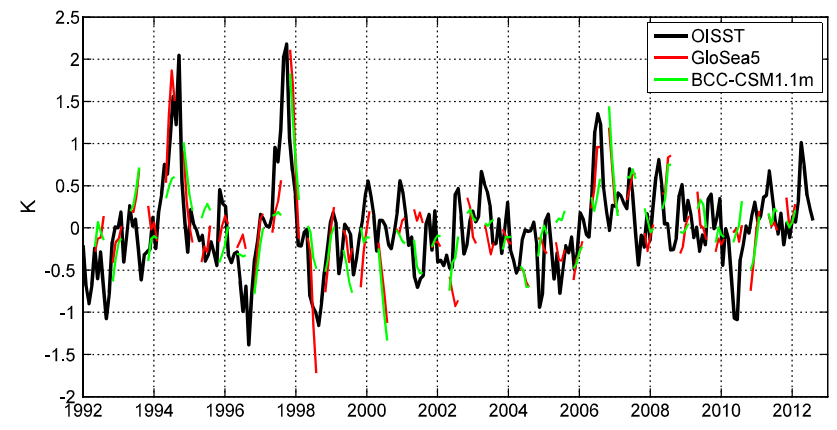

Fig. 10 The IOD index in the observation (black curve), and in the hindcast experiment initialized in May and November by GloSea5 (red curves) and BCC-CSM1.1m (green curve)

BCC-CSM1.1m and GloSea5. As previously discussed, the early westerly wind and subsurface warming acted as precursors in the negative IOD events in 1998 and 2016. As a result, the prediction of the strong negative IOD in 1998 and 2016 is successful although the amplitude is underestimated (overestimated) by BCC-CSM1.1m (GloSea5) due to the biases in mean thermocline depth (Fig. 9). However, the strong negative IOD events in 1996 and 2010 is not predicted by two models (Fig. 10) due to the unclear precursors (Fig. 6).

Previous studies have shown important climate impacts of IOD (Saji and Yamagata 2003), including the severe East African flood during the two strongest positive IOD years in 1994 (Behera et al. 1999) and 1997 (Birkett et al. 1999; Webster et al. 1999). Figure 11 shows the rainfall pattern during the short rain season from October to December (Clark et al. 2003). The precipitation anomalies were clearly anchored by 2016 IOD forcing, with above normal rainfall over the tropical eastern Indian Ocean and the below normal rainfall over the western Indian Ocean and East Africa. The observed pattern is well predicted by BCC-CSM1.1m and GloSea5 (Fig. 11c, d). These successful rainfall predictions result from both the correct 2016 negative IOD prediction and also a realistic IOD-rainfall relationship in both models. Consistent with previous studies (Black et al. 2003; Clark et al. 2003), the correlation of DMI index with East African short rainfall reaches 0.77 in the observations (Fig. 3a). The modulation of IOD on East African rainfall has been studied with atmospheric model simulations (Latif et al. 1999; Ummenhofer et al. 2009). Although other forcings, such as Arctic Oscillation (Gong et al. 2016), can also modulate East African short rain, IOD plays a dominant role (Bahaga et al. 2015). Here we demonstrate that coupled seasonal predictions also capture the observed connection between East African rainfall and IOD. As shown in Fig. 3, the correlation coefficients reach 0.54 and 0.72 for BCC-CSM $1.1 \mathrm{~m}$ and GloSea5, respectively. Given the successful 2016 negative IOD prediction, the East African drought is well predicted 
Fig. 11 Patterns of precipitation anomalies during the East African short rain season (from October to December 2016) in the observations (a) and the real-time prediction initialized in August 2016 by BCCCSM1.1m (c), GloSea5 (d) and their average (d). Numbers denote the spatial correlation coefficients between the observation and real-time predictions

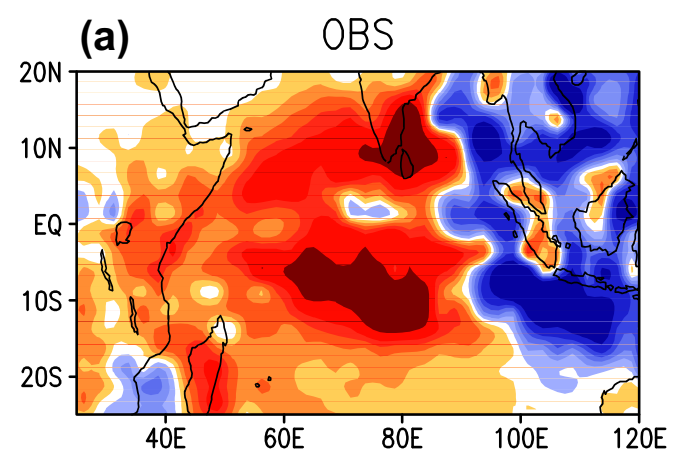

(b) $\quad$ MME $\quad 0.49$
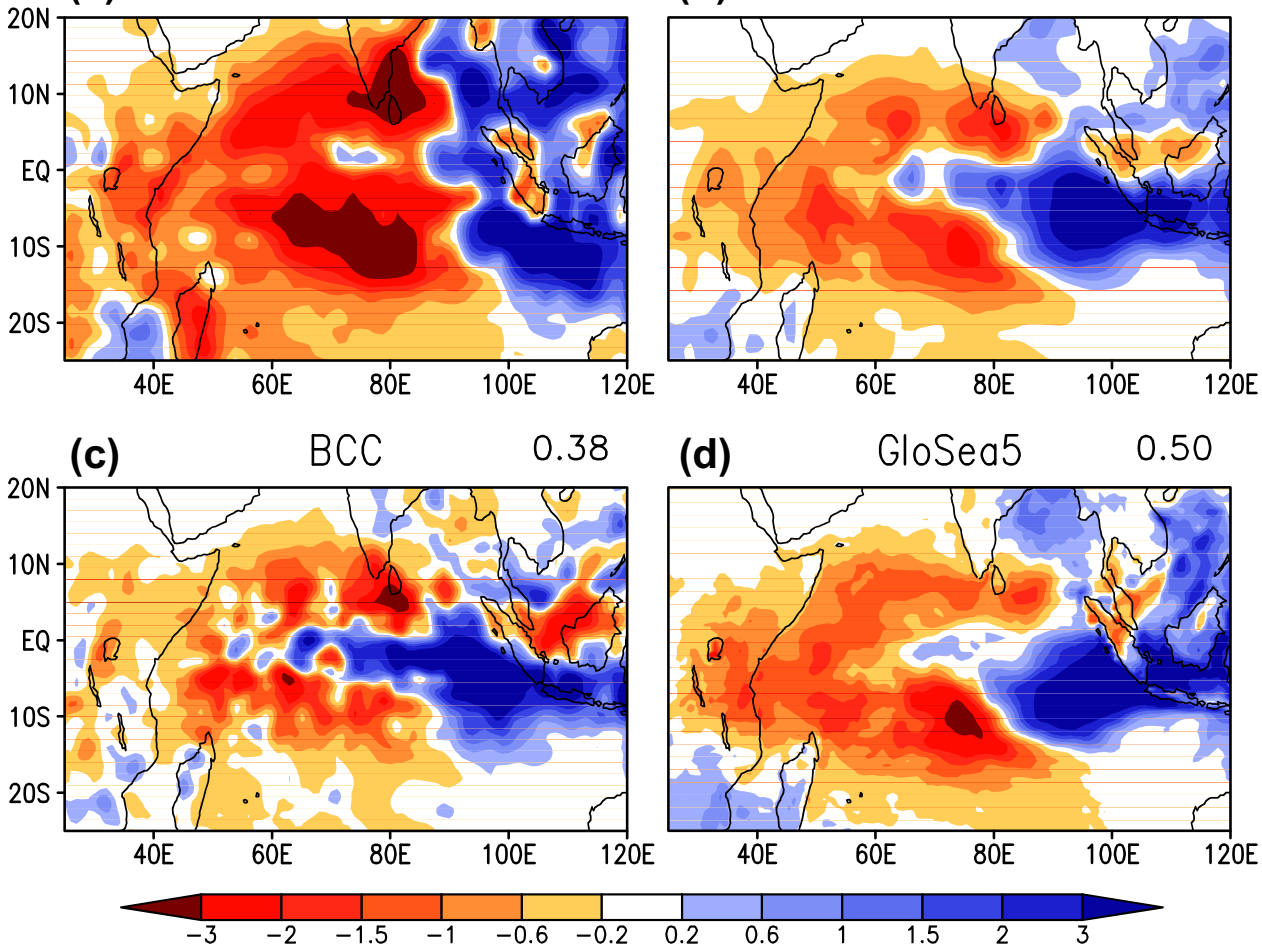

by BCC-CSM1.1m, although the ensemble mean amplitude is smaller than the observations due to the large ensemble spread (Fig. 3b). GloSea5 predicted a reduction of East African short rain by $1 \mathrm{~mm} /$ day $4-6$ months ahead (Fig. 3c), which is very close to the observation.

\section{Summary and conclusion}

An extreme negative IOD event in 2016 caused major climate impacts such as severe East African drought as reported by IAWG. We investigated the dynamics and predictability of the 2016 IOD evolution. We found that the internal variability, involving the WES and thermocline feedbacks, played an important role in 2016 IOD growth during boreal summer. The strong westerly wind anomaly over the equatorial Indian Ocean deepened the thermocline and reduced the wind speed off the Sumatran coast. As a result, increased IODE SST during boreal summer was influenced by the vertical advection and reduced evaporation. Thus, the 2016 IOD event developed quickly in boreal summer and reached a peak of $-1.5^{\circ} \mathrm{C}$ in September 2016, the largest in the period since 1980s. Due to the negative cloud-SST-radiation feedback, the 2016 negative IOD decayed rapidly.

Besides internal variability, possible impact from remote forcing was also studied. A weak La Niña developed in the tropical Pacific during 2016. A moderate atmospheric response was evident, which intensified the Walker circulation and reinforced the westerly wind anomaly over the tropical Indian Ocean during boreal fall. Since the La Niña induced atmospheric response was very weak before July, we suggest that the early westerly wind in May was triggered by active MJOs in May. The subsurface warming immediately followed the MJO induced westerlies in late May. The ocean memory sustained the subsurface warming, and increased the SST off the Sumatran coast when the mean thermocline became shallow after July.

Real-time predictions of the 2016 IOD event were assessed in two prediction systems. Both models successfully predicted the evolution of the 2016 IOD up to 2 seasons ahead. The quick onset, fast decay and peak season of the 2016 negative IOD are all well captured. However, the amplitude is overestimated (underestimated) by GloSea5 (BCC-CSM1.1m). Hindcast experiments confirm the IOD amplitude biases due to the mean state errors in both models. Joint model predictions by BCC-CSM1.1m and GloSea5 give more realistic IOD amplitudes. The successful 2016 IOD predictions result from correct representations of atmosphere-ocean feedback. The reduction of wind speed over eastern Indian Ocean is predicted by both models (Fig. 2), implying realistic WES feedback. Although the subsurface ocean data is unavailable for GloSea5, we show that the observed wind-driven subsurface ocean warming was captured by BCC-CSM1.1m (Fig. 5), indicating a good representation of thermocline feedback in real-time predictions. The 2016 weak La Niña is also 
predicted by both models, offering realistic external forcing for further IOD development. The skillful prediction is also due to the precursor of the early subsurface warming in the eastern Indian Ocean, which increases intrinsic predictability of the 2016 IOD event. Consistent with the successful prediction of the 2016 negative IOD event, the observed East African drought was also be well predicted. Early warning of deficient short rains was obtained 4-6 months ahead, providing potentially important societal benefits from current real-time seasonal prediction systems.

Acknowledgements This work is jointly supported by National Key Research Program and Development of China (2016YFA0602104), National Basic Research (973) Program of China under Grant 2015CB453203, China Meteorological Special Program (GYHY201506013), National Science Foundation (41605116), and the UK-China Research \& Innovation Partnership Fund through the Met Office Climate Science for Service Partnership (CSSP) China as part of the Newton Fund.

Open Access This article is distributed under the terms of the Creative Commons Attribution 4.0 International License (http://creativecommons.org/licenses/by/4.0/), which permits unrestricted use, distribution, and reproduction in any medium, provided you give appropriate credit to the original author(s) and the source, provide a link to the Creative Commons license, and indicate if changes were made.

\section{References}

Allan R, Chambers D, Drosdowsky W et al (2001) Is there an Indian Ocean dipole and is it independent of the El Niño-Southern Oscillation. CLIVAR Exch 21:18-22

Annamalai H, Murttugudde R, Potema J, Xie S-P, Wang B (2003) Coupled dynamics over the Indian Ocean: spring initiation of the zonal mode. Deep Sea Res Part II Top Stud Oceanogr 50:2305-2330

Arribas A, Glover M, Maidens A et al (2011) The GloSea4 ensemble prediction system for seasonal forecasting. Mon Wea Rev 139:1891-1910. doi:10.1175/2010MWR3615.1

Ashok K, Saji NH (2007) On the impacts of ENSO and Indian Ocean dipole events on sub-regional Indian summer monsoon rainfall. Nat Hazards 42(2):273-285

Ashok K, Guan Z, Yamagata T (2001) Impact of the Indian Ocean dipole on the relationship between the Indian monsoon rainfall and ENSO. Geophys Res Lett 28(23):4499-4502

Ashok K, Guan Z, Yamagata T (2003) A look at the relationship between the ENSO and the Indian Ocean dipole. J Meteorol Soc Jpn 81(1):41-56

Ashok K, Guan Z, Saji NH et al (2004) Individual and combined influences of ENSO and the Indian Ocean dipole on the Indian summer monsoon. J Clim 17(16):3141-3155

Bahaga TK, Mengistu Tsidu G, Kucharski F, Diro GT (2015) Potential predictability of the sea-surface temperature forced equatorial East African short rains interannual variability in the 20th century. Q J R Meteorol Soc 141(686):16-26

Baquero-Bernal A, Latif M, Legutke S (2002) On dipolelike variability of sea surface temperature in the tropical. Indian OceanJ Clim 15(11):1358-1368
Behera SK, Yamagata T (2003) Influence of the Indian Ocean dipole on the Southern oscillation. J Meteorol Soc Jpn 81:169-177

Behera SK, Krishnan R, Yamagata T (1999) Unusual ocean-atmosphere conditions in the tropical Indian Ocean during 1994. Geophys Res Lett 26:3001-3004

Behringer DW, Ji M, Leetmaa A (1998) An improved coupled model for ENSO prediction and implications for ocean initialization. Part I: The ocean data assimilation system. Mon Wea Rev 126:1013-1021

Birkett C, Murtugudde R, Allan R (1999) Indian Ocean climate event brings floods to East Africa's lakes and the Sudd Marsh. Geophys Res Lett 26:1031-1034

Black E, Slingo J, Sperber KR (2003) An observational study of the relationship between excessively strong short rains in coastal East Africa and Indian Ocean SST. Mon Wea Rev 131:74-94

Brown A et al (2012) Unified modeling and prediction of weather and climate: a 25-year journey. Bull Am Meteorol Soc 93:1865-1877

Clark CO, Webster PJ, Cole JE (2003) Interdecadal variability of the relationship between the Indian Ocean zonal mode and East African coastal rainfall anomalies. J Clim 16:548-554

Dommenget D (2011) An objective analysis of the observed spatial structure of the Tropical Indian Ocean SST variability. Clim Dyn 36:2129-2145

Dommenget D, Jansen M (2009) Predictions of Indian Ocean SST indices with a simple statistical model: a null hypothesis. J Clim 22(18):4930-4938

Dommenget D, Latif M (2002) A cautionary note on the interpretation of EOFs. J Clim 15(2):216-225

Feng J, Hu D, Yu L (2014) How does the Indian Ocean subtropical dipole trigger the tropical Indian Ocean dipole via the Mascarene high? Acta Oceanolog Sin 33(1):64-76

Francis PA, Gadgil S, Vinayachandran PN (2007) Triggering of the positive Indian Ocean dipole events by severe cyclones over the Bay of Bengal. Tellus A 59(4):461-475

Gadgil S, Vinayachandran PN, Francis PA et al (2004) Extremes of the Indian summer monsoon rainfall, ENSO and equatorial Indian Ocean oscillation. Geophys Res Lett 31(12), doi: 10.1029/2004GL019733

Gill AE (1980) Some simple solutions for heat-induced tropical circulation. Q J R Meteorol Soc 106:447-462

Gong DY, Guo D, Mao R, Yang J, Gao Y, Kim SJ (2016) Interannual modulation of East African early short rains by the winter Arctic Oscillation. J Geophys Res 121:9441-9457

Griffies SM, Harrison MJ, Pacanowski RC, Rosati A (2004) A technical guide to MOM4. NOAA/Geophysical Fluid Dynamics Laboratory, Princeton, p 337

IAWG (2016) Call to action: horn of Africa drought crisis. http:// reliefweb.int/report/ethiopia/call-action-horn-africa-drought-crisis-hornofafricadrought-december-2016. Accessed 09 Dec 2016

Izumo T, Vialard J, Lengaigne $M$ et al (2010) Influence of the state of the Indian Ocean Dipole on the following year's El Niño. Nature Geosci 3(3): 168-172

Ji J, Huang M, Li K (2008) Prediction of carbon exchanges between China terrestrial ecosystem and atmosphere in 21 st century. Sci China (Ser D) 51(6):885-898

Johnson SJ, Turner A, Woolnough S et al (2017) An assessment of Indian monsoon seasonal forecasts and mechanisms underlying monsoon interannual variability in the Met Office GloSea5-GC2 system. Clim Dyn 48(5):1447-1465

Kajikawa Y, Yasunari T, Kawamura R (2003) The role of the local hadley circulation over the Western Pacific on the zonally asymmetric anomalies over the Indian Ocean. J Meteorol Soc Jpn 81(2):259-276

Kalnay et al (1996) The NCEP/NCAR 40-year reanalysis project. Bull Am Meteorol Soc 77:437-470 
Kleeman R, Tang Y, Moore A (2003) The calculation of climatically relevant singular vectors in the presence of weather noise. J Atmos Sci 60:2856-2867

Kug JS, Kang IS (2006) Interactive feedback between ENSO and the Indian Ocean. J Clim 19(9):1784-1801

Latif M, Dommenget D, Dima M, Grötzner A (1999) The role of Indian Ocean sea surface temperature in forcing East African rainfall anomalies during December-January 1997/98. J Clim 12(12):3497-3504

Li T, Wang B, Chang CP, Zhang YS (2003) A theory for the Indian Ocean dipole-zonal mode. J Atmos Sci 60:2119-2135

Liu Y, Zhang R, Yin Y, Niu T (2005) The application of ARGO data to the global ocean data assimilation operational system of NCC. Acta Meteorol Sinica 19:355-365

Liu L, Yu W, Li T (2011) Dynamic and thermodynamic air-sea coupling associated with the Indian Ocean dipole diagnosed from 23 WCRP CMIP3 models. J Clim 24:4941-4958

Liu H, Tang Y, Chen D et al (2017) Predictability of the Indian Ocean Dipole in the coupled models. Clim Dyn 48:2005-2024

Luo JJ, Masson S, Behera S et al (2005) Seasonal climate predictability in a coupled OAGCM using a different approach for ensemble forecasts. J Clim 18(21):4474-4497

Luo JJ, Masson S, Behera S et al (2007) Experimental forecasts of the Indian Ocean dipole using a coupled OAGCM. J Clim 20(10):2178-2190

Luo JJ, Behera S, Masumoto Y et al (2008) Successful prediction of the consecutive IOD in 2006 and 2007. Geophys Res Lett 35(14), doi: 10.1029/2007GL032793

Luo JJ, Zhang R, Behera SK et al (2010) Interaction between El Nino and extreme Indian ocean dipole. J Clim 23(3):726-742

MacLachlan C et al (2015) Global Seasonal forecast system version 5 (GloSea5): a high-resolution seasonal forecast system. Q J R Meteorol Soc 141(689):1072-1084

Madec G (2008) NEMO Ocean Engine, Note du Pole de Modelisation. Institut Pierre-Simon Laplace (IPSL), Paris

Murtugudde R, McCreary JP, Busalacchi AJ (2000) Oceanic processes associated with anomalous events in the Indian Ocean with relevance to 1997-1998. J Geophys Res 105:3295-3306

Rao SA, Luo JJ, Behera SK, Yamagata T (2009) Generation and termination of Indian Ocean Dipole events in 2003, 2006 and 2007. Clim Dyn 33:751-767

Rawlins F, Ballard SP, Bovis KJ et al (2007) The Met Office global four-dimensional variational data assimilation scheme. Q J R Meteorol Soc 133:347-362

Reynolds RW, Rayner NA, Smith TM et al (2002) An improved in situ and satellite SST analysis for climate. J Clim 15:1609-1625

Saji NH, Yamagata T (2003) Possible impacts of Indian Ocean dipole mode events on global climate. Clim Res 25(2):151-169

Saji NH, Goswami BN, Vinayachandran PN et al (1999) A dipole mode in the tropical Indian Ocean. Nature 401:360-363

Schneider U, Becker A, Finger P et al (2011) GPCC Full Data Reanalysis Version 6.0 at $1.0^{\circ}$ : Monthly Land-Surface Precipitation from Rain-Gauges built on GTS-based and Historic Data. doi:10.5676/ DWD_GPCC/FD_M_V7_100

Schott FA, Xie SP, McCreary JP (2009) Indian Ocean circulation and climate variability. Rev Geophys 47:RG1002. doi:10.1029/200 7RG000245

Shi L, Hendon HH, Alves O et al (2012) How predictable is the Indian Ocean dipole? Mon Wea Rev 140(12):3867-3884
Shinoda T, Han W (2005) Influence of the Indian Ocean dipole on atmospheric subseasonal variability. J Clim 18:3891-3909

Song Q, Vecchi GA, Rosati AJ (2008) Predictability of the Indian Ocean sea surface temperature anomalies in the GFDL coupled model. Geophys Res Lett 35(2), doi: 10.1029/2007GL031966

Tennant WJ, Shutts GJ, Arribas A, Thompson SA (2011) Using a stochastic kinetic energy backscatter scheme to improve MOGREPS probabilistic forecast skill. Mon Wea Rev 139:1190-1206. doi:10 .1175/2010MWR3430.1

Ummenhofer CC, Gupta AS, England MH, Reason CJC (2009) Contributions of Indian Ocean sea surface temperatures to enhanced East African rainfall. J Clim 22:993-1013

Wang X, Wang C (2014) Different impacts of various El Niño events on the Indian Ocean Dipole. Clim Dyn 42:991-1005

Wang H, Murtugudde R, Kumar A (2016) Evolution of Indian Ocean dipole and its forcing mechanisms in the absence of ENSO. Clim Dyn 47:2481-2500

Weare BC (1979) A statistical study of the relationships between ocean surface temperatures and the Indian monsoon. J Atmos Sci 36:2279-2291

Webster PJ, Moore AM, Loschnigg JP, Leben RR (1999) Coupled ocean-atmosphere dynamics in the Indian Ocean during 1997-98. Nature 401:356-360

Wheeler MC, Hendon HH (2004) An all season real-time multivariate MJO index: development of an index for monitoring and prediction. Mon Wea Rev 132:1917-1932

Winton M (2000) A reformulated three-layer sea ice model. J Atmos Ocean Technol 17:525-531

Wu T, Yu R, Zhang F (2008) A modified dynamic framework for the atmospheric spectral model and its application. J Atmos Sci 65:2235-2253

Wu T, Yu R, Zhang F (2010) The Beijing Climate Center atmospheric general circulation model: description and its performance for the present-day climate. Clim Dyn 34:123-147

Xie P, Arkin PA (1997) Global precipitation: A 17-year monthly analysis based on gauge observations, satellite estimates, and numerical model outputs. Bull Am Meteorol Soc 78:2539-2558

Yamagata T, Behera SK, Rao SA et al (2003) Comments on "Dipoles, temperature gradients, and tropical climate anomalies". Bull Am Meteorol Soc 84:1418-1422. doi:10.1175/BAMS-84-10-1418

Yamagata T, Behera SK, Luo JJ et al (2004) Coupled ocean-atmosphere variability in the tropical Indian Ocean. Earth climate: the ocean-atmosphere interaction. Geophys Monogr 147:189-212

Yang Y, Xie SP, Wu L et al (2015) Seasonality and predictability of the Indian Ocean Dipole mode: ENSO forcing and internal variability. J Clim 28(20):8021-8036

Yu JY, Lau KM (2004) Contrasting Indian Ocean SST variability with and without ENSO influence: a coupled atmosphere-ocean GCM study. Meteorol Atmos Phys. doi:10.1007/s00703-004-0094-7

Yu JY, Mechoso CR, McWilliams JC et al (2002) Impacts of the Indian Ocean on the ENSO cycle. Geophys Res Lett 29(8), doi: 10.1029/2001GL014098

Yuan Y, Yang H, Zhou W, Li CY (2008) Influences of the Indian Ocean dipole on the Asian summer monsoon in the following year. Int J Climatol 28:1849-1859

Zhao M, Hendon HH (2009) Representation and prediction of the Indian Ocean dipole in the POAMA seasonal forecast model. Q J R Meteorol Soc 135(639):337-352 